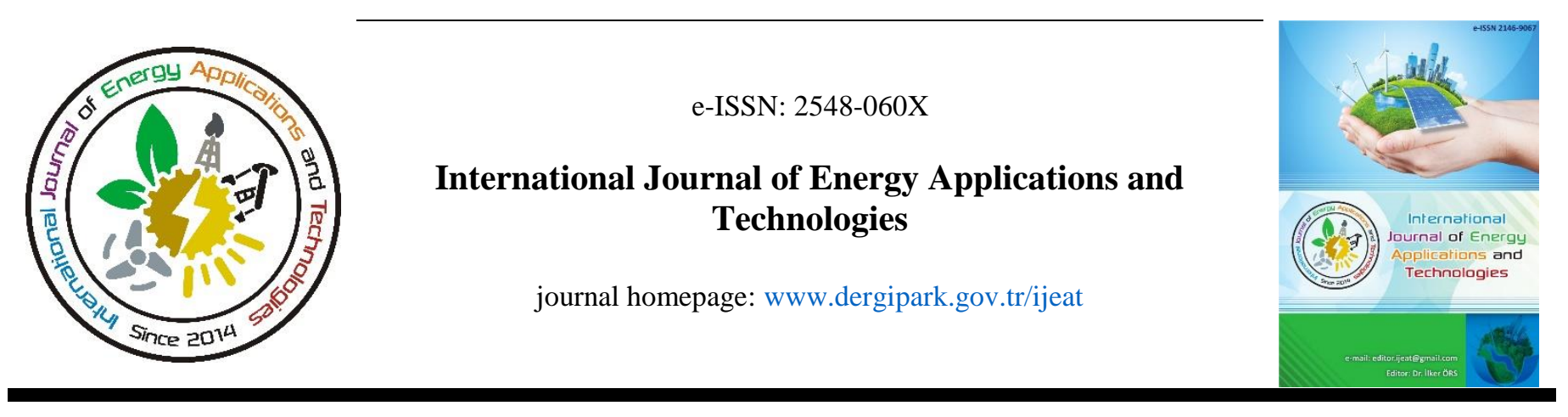

Original Research Article

\title{
A new intelligent system design for cleaning the photovoltaic solar panel surface
}

\author{
Mümtaz Mutluer ${ }^{1, *}$, Abdurrahim Erat ${ }^{2}$ \\ Electrical and Electronics Engineering Department, Faculty of Engineering and Architecture, Necmettin Erbakan University, Turkey \\ Institute of Science and Technology, Necmettin Erbakan University, Turkey
}

\begin{abstract}
ARTICLE INFO
* Corresponding author mmutluer@erbakan.edu.tr

Received January 3, 2019

Accepted March 23, 2019

Published by Editorial Board Members of IJEAT

(C) This article is distributed by Turk Journal Park System under the CC 4.0 terms and conditions.
\end{abstract}

doi: $10.31593 /$ ijeat.507861

\begin{abstract}
Nowadays electricity is generated by solar energy through photovoltaic solar cells and the system efficiency developed in this direction is being investigated. The efficiency of the photovoltaic panels used to transform solar energy into electricity is utmost importance. Dusting, equipment which are used for photovoltaic systems (DC conductors, inverter, panel interior design, etc.), shadowing, amount of radiation and many other factors affect to the efficiency of photovoltaic panels. Some of these are resolved in the installation of the system, while others are changed over time. For a good efficiency of the system during operation, at bottom, photovoltaic panel surface must be kept clean and so it can be absorb more effective solar radiation. The surface cleaning is empiric in many studies which manual or automatic; it can actually be by an intelligent system. In this study, an intelligent cleaning system based on fuzzy logic with arduino microcontroller was designed to automatically clean the photovoltaic panel surfaces. Thanks to the membership functions of the fuzzy logic as temperature, shadowing, dusting and output current of the panel, the designed system is enabled to operate efficiently. Two membership functions of each of these input functions have been determined. Detailed information about the membership functions of the inputs of the system is given in the system design section. These membership functions decide whether the system will be activated or not. The design purpose is to minimize the efficiency losses due to dusting and dirt on the panel surface and to allow for maximum electrical energy production. As a result, without waiting for the cleaning period, the loss of energy production is eliminated and the efficiency was increased by $15-20$ percent.
\end{abstract}

\section{Introduction}

Solar energy is a clean energy source that is produced from direct sunlight, without any harmful gas emissions. The sun's energy which is come to the earth is 20 thousand times more than the energy consumed in a year in the world and so it is a great source of energy. Today, the most needed energy type is electricity energy because of easily convertible. The fact that most of the environmental problems arising from the use of traditional energy sources are not in electricity generation by solar power, makes this energy source an alternative to traditional energy sources [1].
Electric energy can be produced with photovoltaic (PV) panels from solar energy which is an infinite heat and light source. During this transformation, all of the radiation coming to the surface of the PV panels cannot be converted to electricity. Many losses occur during the related photovoltaic event. These losses are reflection, shadowing, contamination, differences in module specifications, low radiation, temperature, conductor, and inverter losses [2-8]. Factors such as choosing the appropriate geographical location and beam angle, selecting the right equipment and kept the surfaces of the panels clean should be considered to minimize these losses [8-10]. 
One of the most important ways to increase the efficiency of the PV panels is to keep panel surfaces clean. Different studies from manual to automatic for the PV panel surface cleaning have been used [11-13]. Some empirical studies are industrial applications. Unfortunately, these studies are far from any scientific innovation and inefficient. So they are just doing primitive cleaning and the efficiency of working in this direction is low. Moreover, other academic studies are not at the desired level in terms of the overall system efficiency, although these studies focus on the new concept of mechanical, electrostatic or chemical cleaning of the PV panel surface [14-20]. In this case, it is necessary to utilize artificial intelligence and it is thought that the system efficiency will increase and the operating costs will decrease. Especially, because of the spread of solar energy plants in huge areas, the choice of intelligent automatic cleaning systems will allow very serious efficiency gains. This study is also the result of such a prediction.

In order to properly clean the surface of the PV panel, the pollution must be separated from the factors affecting electricity generation from the aforementioned solar energy. In other words, determining the pollution by making a wise choice will increase the efficiency and economy of electricity generation and the system in general. In the literature, there have been studies that follow the output of the panel (voltage and power) or factors that influence the power generation of the panel [21-23]. However, each parameter in these studies has been examined independently or only for information purposes. Therefore, it is under expectations from the intelligent system. In this work, four input parameters are distinguished by fuzzy logic to clear the panel surface. For this, thanks to the application developed with the Arduino microcontroller, the instantaneous energy consumption of the system is increased by $15-20 \%$.

\section{Solar Energy and Photovoltaic Cells}

\subsection{Solar cells (photovoltaic cells)}

Solar cells (photovoltaic cells) are semiconductor materials that directly convert the sunlight which is coming to their surface into electrical energy. The areas of the solar cells whose surfaces are formed as square, rectangular, circular shape are generally about $100 \mathrm{~cm}^{2}$ and their thickness varies between $0,1-0,4 \mathrm{~mm}$. Solar energy is converted to electrical energy up to $40 \%$ efficiency depending on the structure of the solar cell and the semiconductor material used [1]. In order to increase the electrical energy obtained, a large number of solar cells are connected in parallel or in series and mounted on a surface which is called solar cell module or photovoltaic module. The PV system was shown in Fig. 1 [1]. The photovoltaic effect is a physical process by which a photovoltaic cell converts solar radiation to electricity. As shown in Fig. 2 [1], photons strike the surface of semiconductor materials for release the electrons from atoms. The source of the radiation from the sun is the energyincluding photons. Some of the photons on the photovoltaic cell are absorbed by the cell, some are reflected and the remaining part is transferred through the cell to the electron in the atom of the semiconductor material. Thanks to this newly acquired photon energy; electron gains the ability to escape its normal position for a single atom in a semiconductor material to be part of the current in an electric circuit.

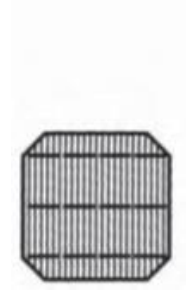

Cell

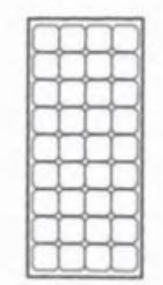

Module

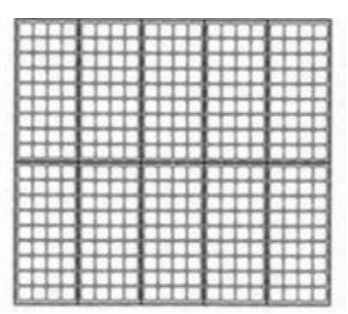

Array
Figure 1. Photovoltaic solar cell

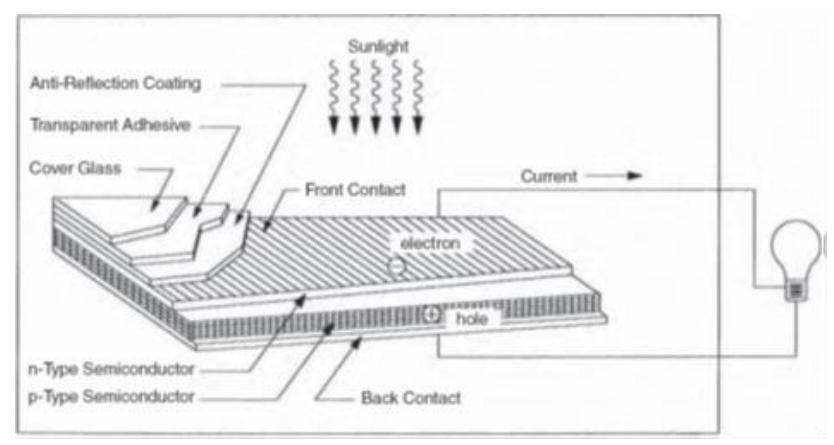

Figure 2. The working principle of the solar cell

\subsection{Efficiency of solar cells}

The efficiency of the PV panels are determined under standard test conditions of $1000 \mathrm{~W} / \mathrm{m}^{2}$ radiation, $25^{\circ} \mathrm{C}$ temperature and 1.5 mass air ratio (AirMass). When the efficiency of a photovoltaic cell is determined, current and voltage values are determined under appropriate conditions and the characteristic current-voltage (I-V) curve of the photovoltaic cell is drawn $[1,2,6,24]$. Thanks to the I-V characteristic, the factors affecting the efficiency of photovoltaic cells are determined and efficiency calculations are made.

The energy obtained in a PV system depends on many factors. Some of these factors are the nominal characteristic values of the components constituting the PV system, system structure, geographical position of the system, pollution, shadowing, temperature, structures around the place of installation and some faults that may occur during operation, a general notation is given in Fig. 3 [3, 8]. 


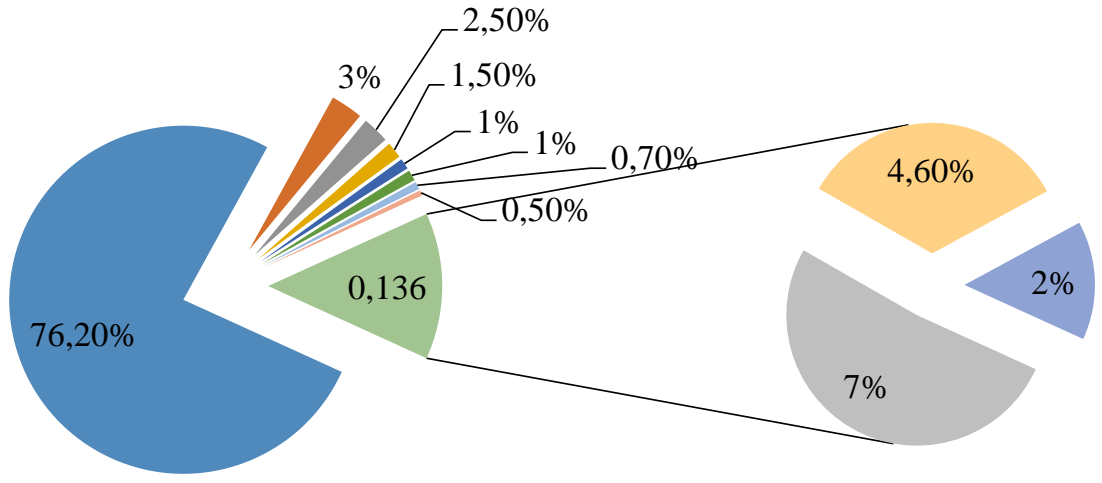

Energy into grid

- Inverter

$\square$ Reflection

- Irradiation

- Spectrum

- DC Cable

Array mismatch

AC Cable

Shadowing

Temperature

Dusting

Figure 3. Losses in PV system

\subsection{Pollution on the photovoltaic panel surface}

Pollution effect is the accumulation of dust or dust derived items on the PV panels. Pollution on the panel surface can seriously affect the energy production efficiency of the PV panel. Power losses vary for different climates depending on the pollution. Investigations on the effect of dust on the efficiency of PV panels, especially in low rainfall areas, show that between $10 \%$ and $40 \%$ of the dust-related losses [7, 19, 25].

The size and properties of dust particles in the air lead to different effects on the PV panel modules [26-28]. The distribution of these particles in the world can be observed in Fig. $4[8,17,28]$. Investigations on the dust effect on panel efficiency show that in the areas with low rainfall, the tobacco-related losses reached or exceeded $15 \%$. If the panel surface cleaner is not detected in the shortest time, it can cause permanent damage to the panel. The way to avoid this large loss of efficiency is to instantly keep the modules clean. For this, PV panel data or factors affecting the efficiency should be followed.

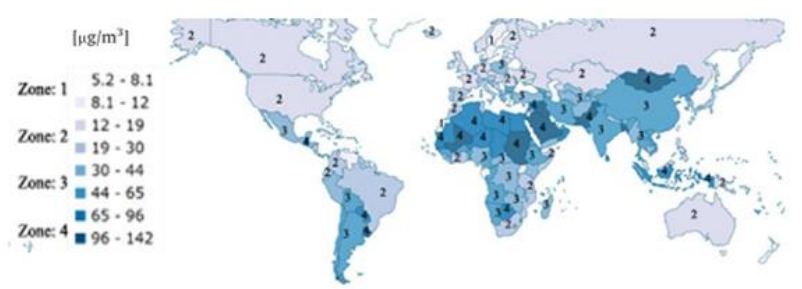

Figure 4. Distribution of dust sizes in the world according to the countries

\section{Fuzzy Logic}

\subsection{Fuzzy logic definition}

Fuzzy logic is a multi-logic system that is formed against the binary logic system and defines the membership grades of the variables that are used in daily life, revealing at what rates and conditions the events can take place. Lotfi A. Zadeh, who introduced the fuzzy logic system, by studying the aircraft to describe the aircraft approaching ships, can handle ambiguous data and so he has taken the base of the fuzzy logic. Fuzzy logic is able to calculate with words. In other words, it is a logic system that imitates the ability of people to think and decide unclear fuzzy expressions. Fuzzy logic has a characteristic that indicates the characteristics of real life, interacts with the decision maker during the solution phase and allows it to participate in the decision phase [29].

\subsection{Fuzzy logic system structure}

Fuzzy logic system consists of entry, database, rule base, blurring unit, fuzzy inference mechanism, clarification unit and output unit [29]. In the fuzzy logic system, the number of data coming into the database is a number, and the information obtained by the creation of the fuzzy logic rules and the operation of the inference engine is output as a function of the inputs. The units of this system are schematically shown in Fig. 5.

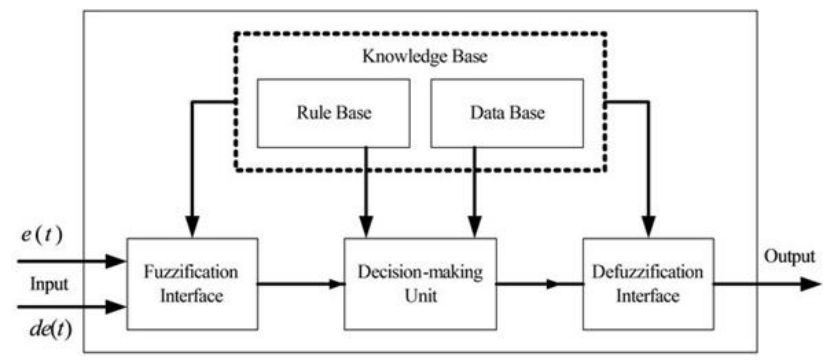

Figure 5. General fuzzy logic structure

\subsection{Fuzzy logic membership function}

Membership functions are the factors that determine the limits in the system and directly affect the result. By 
determining the appropriate membership function for the system, the fuzzy system increases the accuracy of the decision. According to the desired result, the membership functions show that fuzzy logic has a flexible structure.

There are many membership functions for the fuzzy logic system. All membership functions are continuous, normal and convex. Moreover, in the applications triangular, trapezoidal, and Gaussian membership functions are usually used. In this study, triangle membership was used and it was defined, other membership functions can be viewed in the literature.

\section{Triangle membership function}

The triangular membership function is used for the fuzzy problems in which the linear increase and the linear decrease between the maximum and minimum values are concerned. When the membership function is selected in the fuzzy system design, the most used method is the triangle membership function method [29]. The graph of the triangular membership function is given in Fig. 6.

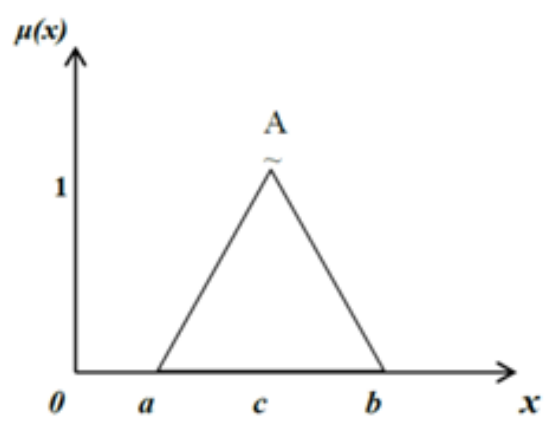

Figure 6. Triangle membership function

The mathematical expressions of the triangular membership functions are as follows.

$\mu_{A}(x)=\left\{\begin{array}{c}a\left(\frac{x-a}{c-a}\right) a \leq x \leq c \\ a\left(\frac{b-x}{b-c}\right) c \leq x \leq b \\ 0 \quad \text { other }\end{array}\right.$

\section{The Cleaning System Design of PV Panel Surface}

\subsection{Architecture of the project}

In this study, an intelligent automatic cleaning system has been designed that allows the panel surfaces to be automatically cleaned. The architecture of this system is based on fuzzy logic system with arduino microcontroller. The system can automatically move and clean the panel surface thanks to software embedded in the microcontroller according to the environmental factors (sunlight, environmental pollution etc.) and the efficiency which is obtained from the panel. The architectural structure and the view of the system designed were given in Fig. 7 and Fig. 8.

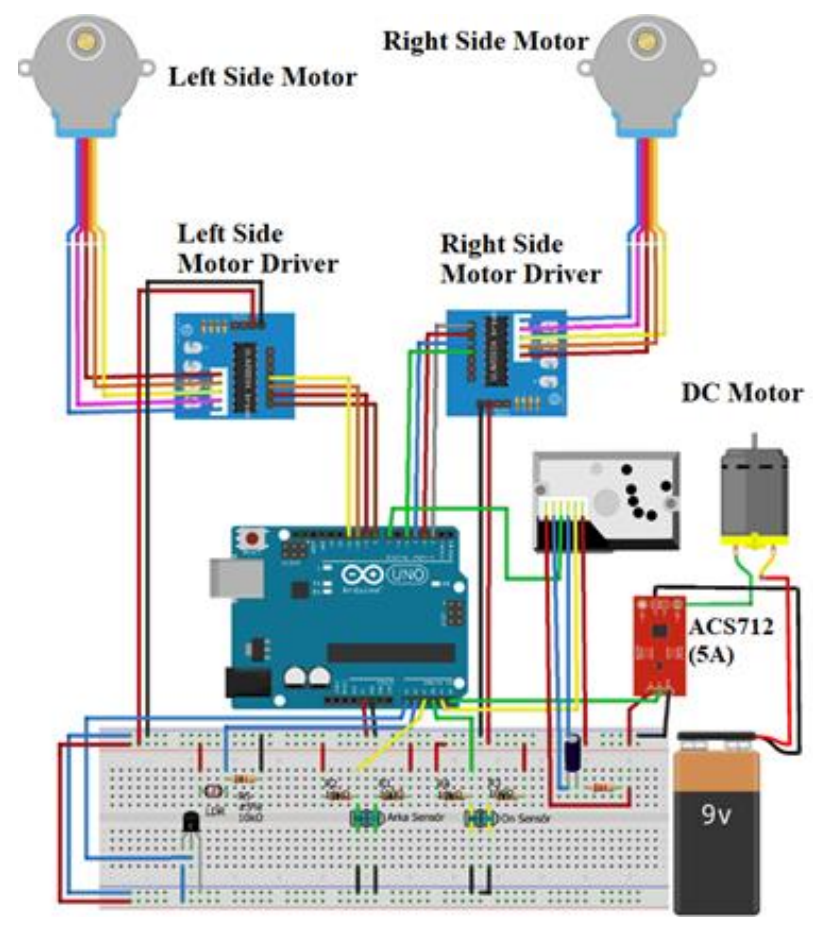

Figure 7. Architecture of the system

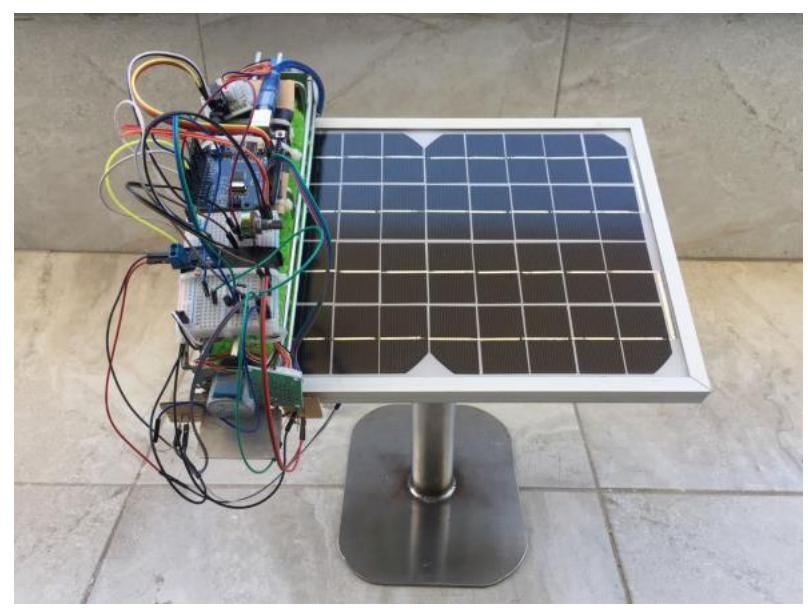

Figure 8. The appearance of the realized system

\subsection{Fuzzy logic structure of the cleaning system}

In this design, an artificial intelligence method based on the fuzzy logic system was used. As system inputs; the temperature, panel surface pollution (dusting), panel exit current and shadowing data which are affecting the efficiency of the PV panel were chosen. As shown in Fig. 9, for the most accurate solution of the fuzzy logic problem these four data are designed as inputs to the fuzzy logic system. The automatic panel surface cleaning system, based on fuzzy logic, activates the system after these four data are blurred each other and defuzzification for the optimal solution. In this way, it is aimed to obtain the most appropriate and correct solution of the problem. 


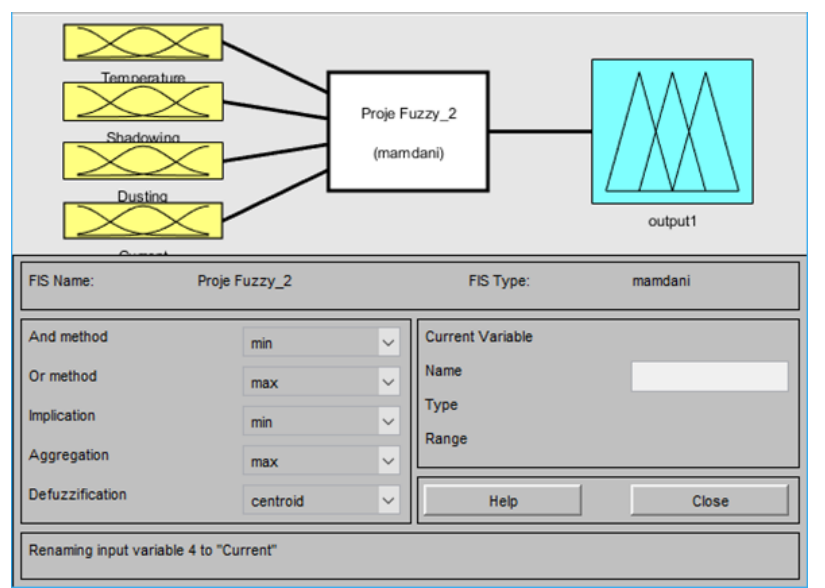

Figure 9. Design of fuzzy logic system inputs and outputs

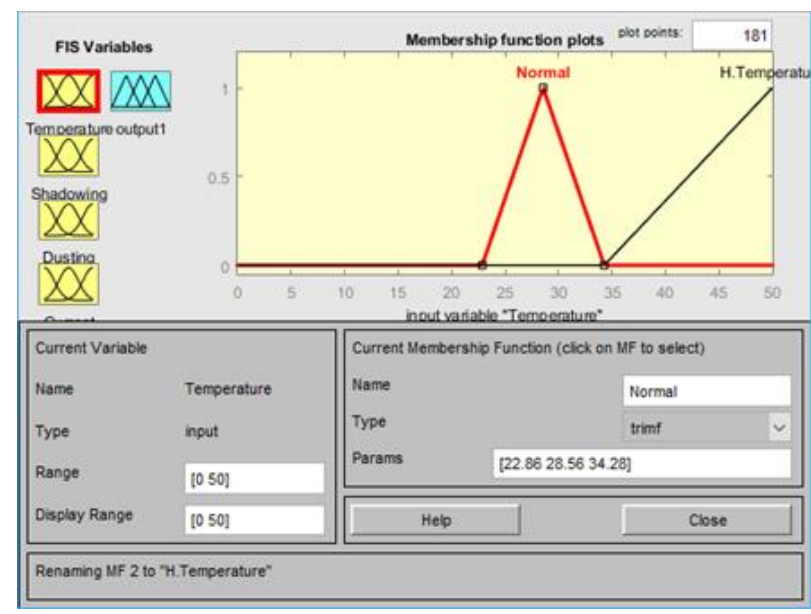

a) temperature

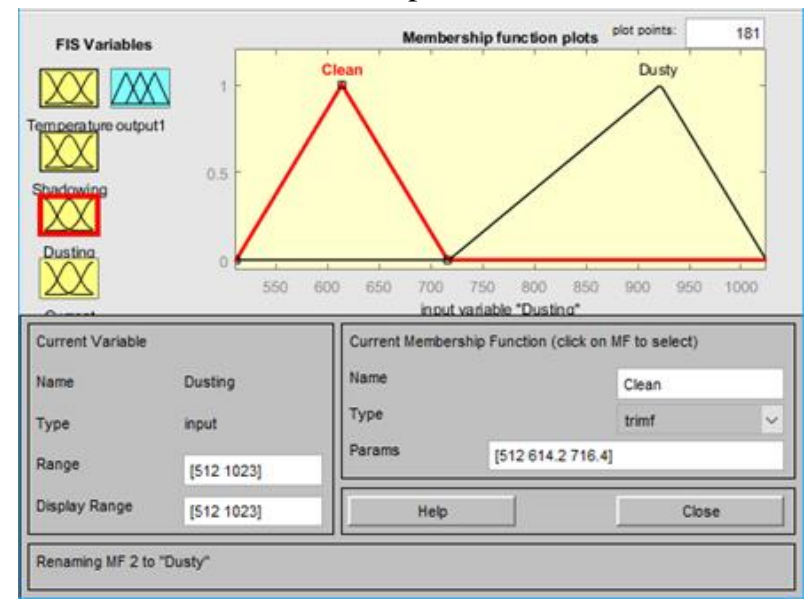

c) pollution

\subsection{Membership functions of each input}

For the inputs of temperature, shadowing, pollution, and current two membership functions were defined e.g. normal and high temperature (H.temperature), shadowy and normal, clean and dirty, low current (1.current) and normal current (n.current), respectively. Fig. 10 shows graphs of these membership functions in triangular membership format and the specified ranges.

\subsection{The operating rules of the fuzzy logic system}

For the correct solution of a fuzzy problem the rules are defined according to the inputs data. The purpose of creating these rules is to get the most accurate solution of the system. Fig. 11 shows the rules of the fuzzy logic system and Fig. 12 reflect on impact.

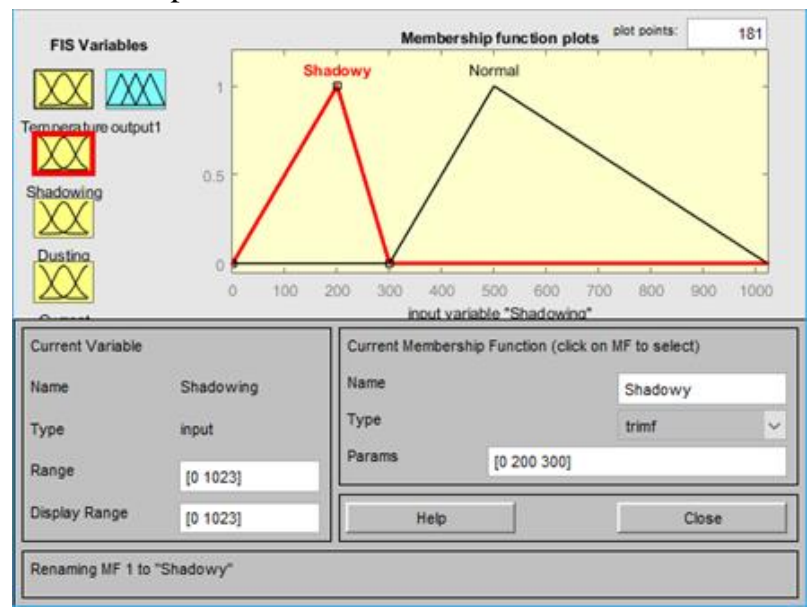

b) shadowing

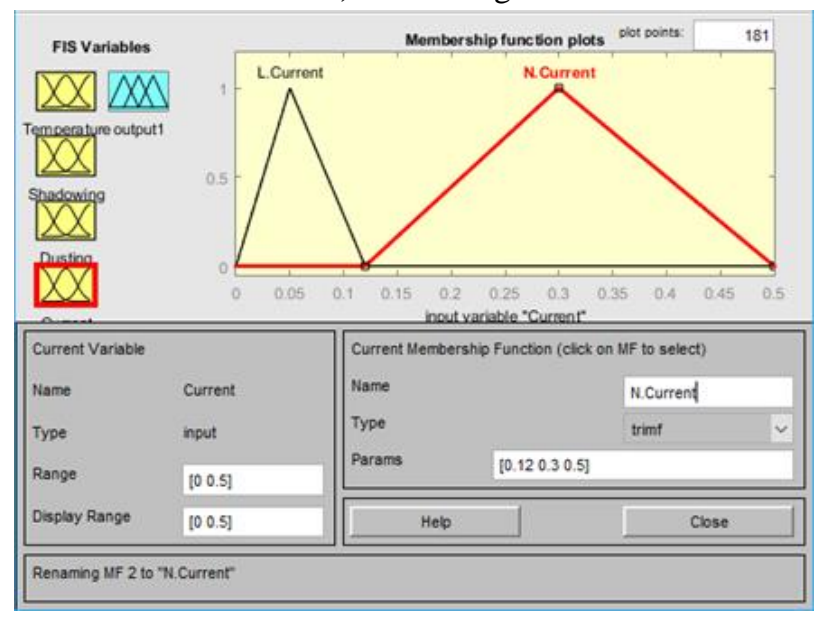

d) current

Figure 10. Graphs of the membership functions

Designed to increase the efficiency of the photovoltaic panel, temperature, shadowing, dusting and output current of the panel are selected as input functions for the fuzzy logic system. Two membership functions have been determined for each of these input functions which are detailed information about these membership functions is given above. The main purpose of selecting these membership functions of these input functions and input functions is to ensure the efficient operation of the designed system. In order for the system to start, the membership functions must provide all values in the specified intervals. For example, because there is no sunlight in the darkness of the night, the 
system only decides other existing membership functions according to their values and does not take action. These four input data and eight membership function requirements for these inputs data must be satisfied. Fuzzy logic method was chosen to prevent unnecessary operation of the system. Detailed information on the selected range of the selected membership functions is given in the section above.

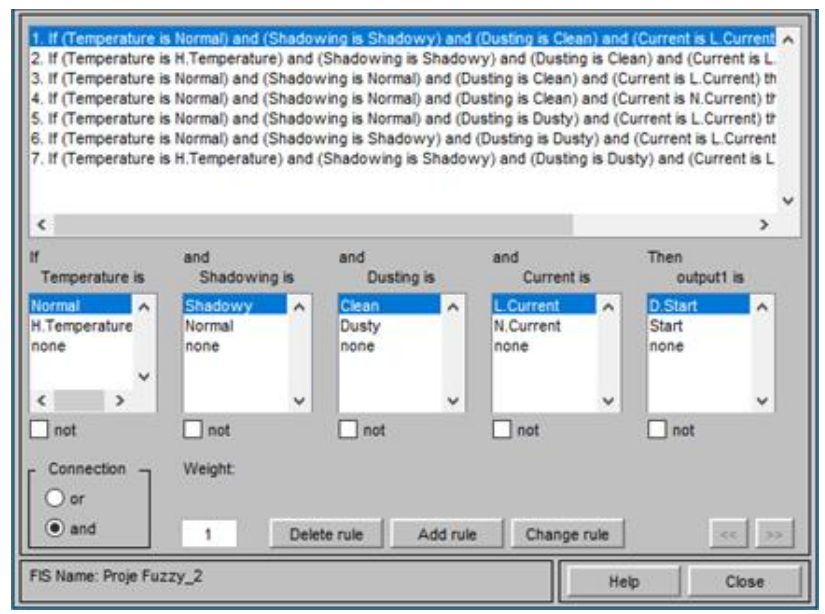

Figure 11. Determination of fuzzy system rules

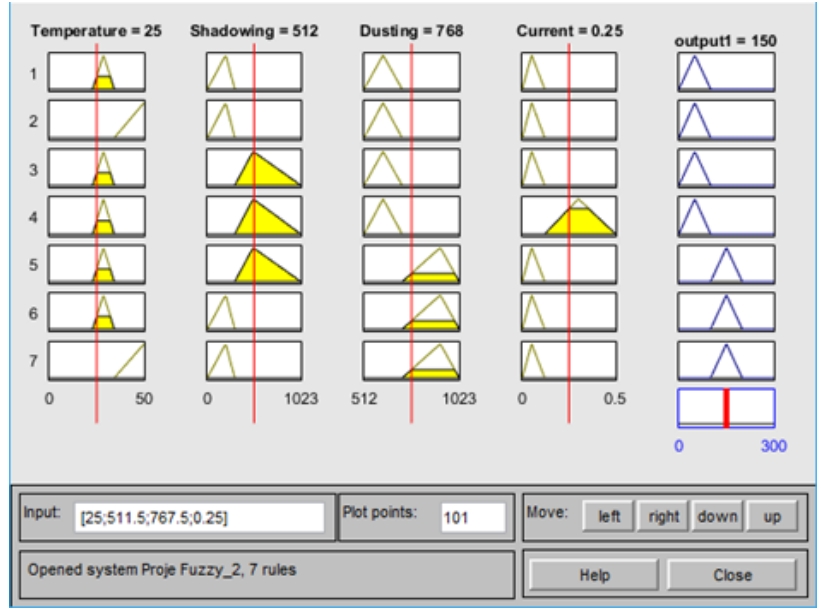

Figure 12. Demonstration of fuzzy system rules

As a result of the specified input data firstly blurred and then defuzzification, a decision outcome of the system is obtained. The designed system starts to clean the surface of the panel by moving on the panel surface according to the degree of this decision. Having achieved this exit decision, the value ranges of the membership functions of the inputs of the system are determinative.

\subsection{Working principles of the system}

In the design fuzzy logic system, temperature, shadowing, pollution, and panel output current were determined as the inputs of the system in order to the system to be able to move at the right time and in the right way. Membership functions were assigned according to these inputs. According to the four input conditions specified, the incoming data is blurred for correct solution of the fuzzy system. Then, the data blurred in accordance with the determined conditions are clarified for the correct solution. Accurate solution of the system is obtained thanks to the data being clarified. The designed automatic cleaning system also moves on the panel surface in the direction of this output data. The system that started to move has traveled to the end of the panel and comes back to its starting position. The next move of the system is realized by correct solution of the fuzzy system by gathering appropriate conditions again.

\subsection{System output for unloaded}

As seen in Fig. 13, the decision level output of the fuzzy system is obtained according to the defined intervals of membership functions of temperature, pollution and shadowing inputs, which are inputs of the system. As the intervals of membership functions of system inputs change, the output decision level of the system also changes.

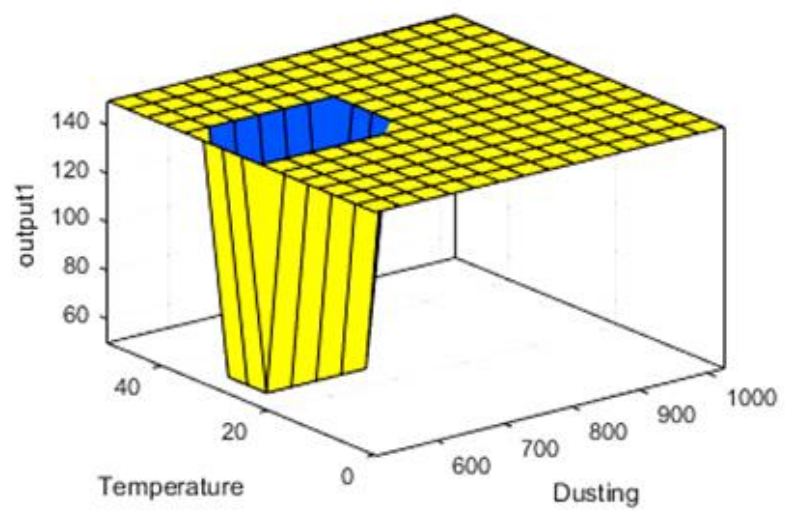

(a)

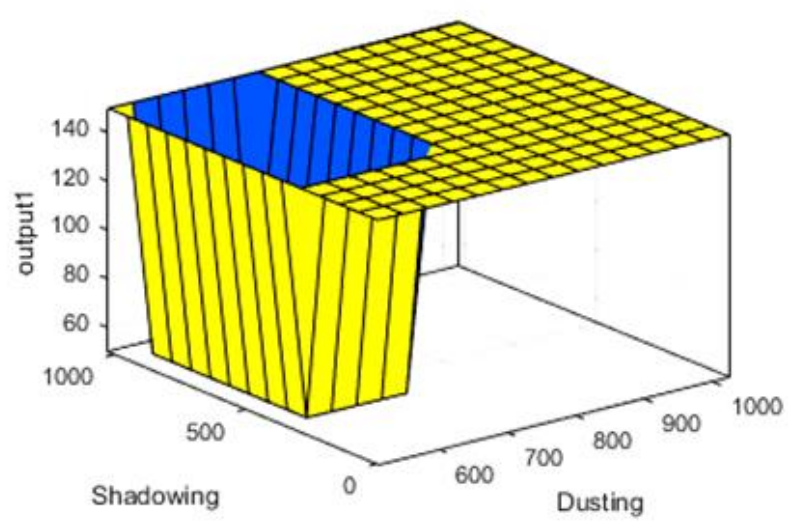

(b)

Figure 13. (a) Output data graph according to temperature and pollution data (unloaded)

(b)Output data graph according to shadowing and pollution data (unloaded)

\subsection{System output for loaded}

As shown in Fig. 14 and Fig. 15, when the system is on load and the panel is dusty, the resulting output current value 
changes with the output current value after system operation. After the designed system moves and cleans the panel surface, the resulting panel output current value increases and therefore the decision level of the fuzzy logic system also changes.

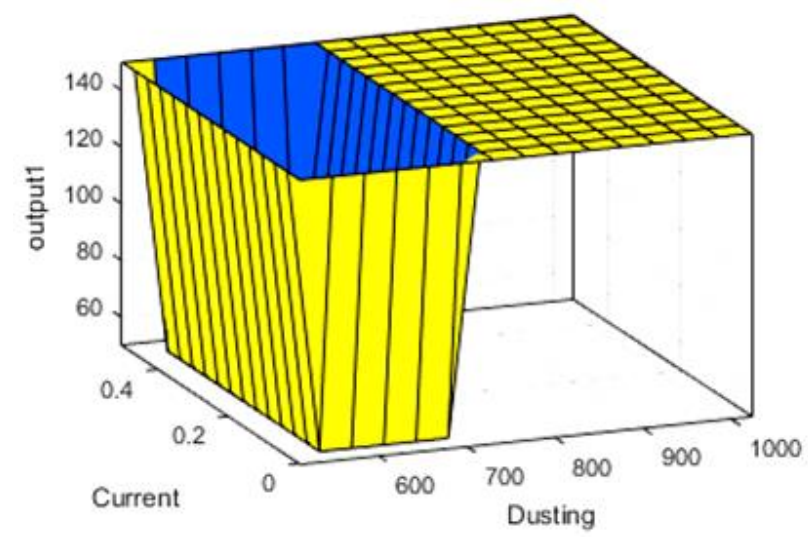

(a)

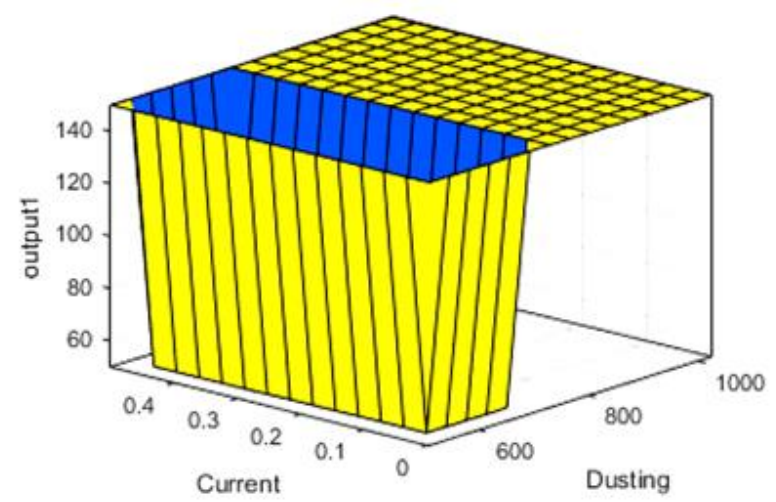

(b)

Figure 14. (a) Output graph according to current and pollution data (panel loaded) (output current: $0.13 \mathrm{~A}$ ) (panel is dirty)

(b)Output graph according to current and pollution data (panel loaded) (output current: $0.11 \mathrm{~A}$ ) (panel is dirty)

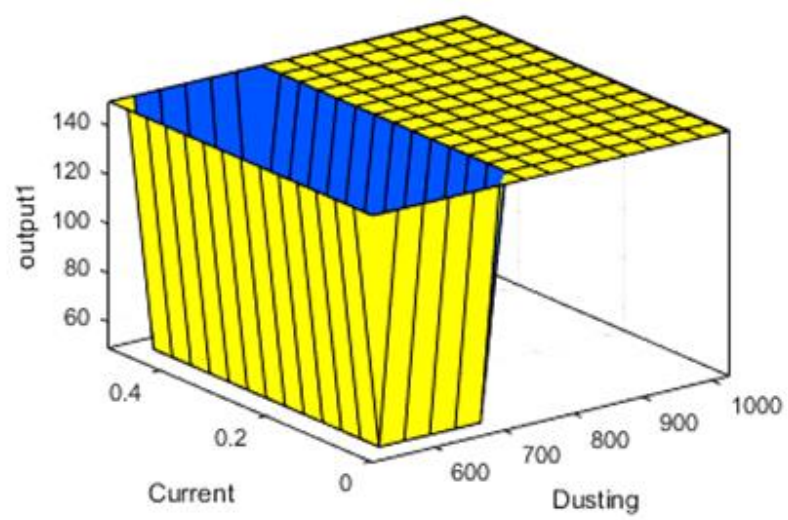

Figure 15. Output graph according to current and pollution data (panel loaded) (output current: 0.25A) (panel is clean)

\subsection{Research results and analysis}

In recent years, there has been a rapid increase in the number of solar energy power plants that are based on conversion of solar energy into electricity. It is also important to investigate the general losses in the conversion of solar energy to electricity in these solar power plants. Today, the number of large-scale power plants performing energy production in the "Gigawatts" range increases day by day. While investigating the efficiency performances of photovoltaic solar power plants, many factors are come across. The measurement of the current-voltage values of photovoltaic solar cells under different radiation intensities and different operating conditions is very important because it shows the performance of the PV system. Power output and efficiency of photovoltaic solar cells depend on many parameters such as radiation intensity, working temperature and climate conditions. Photovoltaic panel surfaces must be kept clean to absorb more effective sunlight in order to obtain electrical energy with high efficiency from PV panels. The pollution factor is the accumulation of dust and like dust derivatives on PV panels. The dust that accumulates on the panel is seriously affecting the efficient production of electric energy with PV panels. In the seasons when the amount of rainfall is very low or when there is no precipitation, the pollution rates due to dust which can be measured in short time is about 10 $40 \%$.

Energy conversion in PV panels varies according to the panel structure and average efficiency is around $25 \%$. This efficiency is also reduced over time by the accumulation of dust, dirt, pollen and various dust particles on the panel. Located in a dirty and dusty geography, especially in solar energy plants established in the desert, the efficiency due to dust shows a decrease around 40\%. Cleaning and maintenance must be done every week to get maximum efficiency from the PV panels. But this is a rather cumbersome and costly process for solar power plants that have been spread over a very large area. One of the most important ways to overcome these challenges is to use automated smart panel surface cleaning system.

This study aims to prevent efficiency losses due to pollution of the surfaces of PV panels. A maximum output current of 0,6A was obtained from the PV panel used for this study under nominal conditions $\left(1000 \mathrm{~W} / \mathrm{m}^{2}\right.$ radiation, $25^{\circ} \mathrm{C}$ cell temperature and clean panel surface). In the tests performed, it was observed that there was serious loss of efficiency when the panel surface was dusty. In these tests it was determined that the output current of the PV panel was at low levels (0,09-0,12A), while the radiation and temperature were appropriate. This fuzzy-based system that detects this low current level has moved on the panel surface. As a result of the movement of the system, it was observed that the panel output current rose to $0,25 \mathrm{~A}$. As a result, it has been determined that due to the automatic panel surface cleaning design, which can act as a fuzzy logic base, the loss due to the dust is around $15-20 \%$. The automatic system based on 
the fuzzy logic principle is activated by the perception of the efficiency loss due to the fact that the panel is dirty.

The main purpose of this article is to investigate the effects of substances such as powders and derivatives on the efficiency of photovoltaic solar panels. In this study, this issue is mainly discussed. The stepper motors in the system are powered externally. The energy produced by the photovoltaic solar panel does not have a direct relation to the energies of the stepper motors. Stepper motors with slow running characteristics are preferred for more efficient cleaning of the panel surface. This design is a prototype design. For large photovoltaic solar panel areas, an improved version of this design should be preferred. The speed of the system is entirely proportional to the size of the solar power plant. The magnitude and smallness of the photovoltaic solar panel array directly affects the cleaning speed of the designed system.

Designed as a prototype, this model is also suitable for industrial design to check the effect of other input parameters for example, to provide the appropriate temperature value for maximum energy production. Considering the size and spreading area of solar power plants, if this model which was firstly introduced, is industrially designed and used in solar energy plants very significant gains will be achieved at efficiency point.

\section{Conclusion}

In this study, the pollution (dusting) factor which is an effective factor on the efficiency of the PV panels was investigated. As part of the researches, has been designed an arduino microcontroller and a fuzzy logic-based intelligent system that automatically cleans the surfaces of the PV panels. For this achieved fuzzy logic-based design, the output current of the PV panel, temperature, pollution and shadowing factors were defined as inputs for the fuzzy logic system. Two membership functions were selected for these four input data. In the fuzzy logic method used in system design, membership functions were first blurred according to the determined data ranges. Then, a clearing step was taken in the light of these data. After blurring and clarification, the fuzzy logic method produced a decision. This decision degree was obtained in order to ensure the efficient operation of the system. According to the decision level of the fuzzy logic output, the system moves on the panel surface and cleans the surface of the panel to increase the output efficiency. After the system completes its movement, dust and dust derivative particles deposited on the panel surface have been found to reduce panel efficiency by $15-20 \%$. In a couple of experiments performed for this study, an average improvement of $17 \%$ was obtained in the efficiency of the photovoltaic panel by means used in the fuzzy logic based microcontroller control method. As a consequence, the recommended system increases efficiency by up to $17 \%$ compared to routine cleaning.

\section{References}

[1] Mukund R. Patel, "Wind and solar power systems design, analysis, and operation", New York, U.S.A, 2006.

[2] A. Chouder, S. Silvestre, "Analysis model of mismatch power losses in PV systems", Journal of Solar Energy Engineering, Vol. 131, Issue 2, 2009.

[3] S. Ekici and M. A. Kopru, "Investigation of PV system cable losses", International Journal of Renewable Energy Research, Vol.7, No.2, 2017.

[4] F. Touati, A. Massoud, J. Abu Hamad and S. A. Saeed, "Effects of environmental and climatic conditions on PV efficiency in Qatar", International Conference on Renewable Energies and Power Quality (ICREPQ), 2013.

[5] M. Hosenuzzaman, N. A. Rahim, J. Selvaraj and M. Hasanuzzaman, "Factors affecting the PV based power generation", 3rd IET International Conference on Clean Energy and Technology (CEAT), 2014.

[6] D. K. Chaturvedi, S. Sharma, "An experimental study and verification of the facts related to factors affecting the performance of solar PV systems", Fifth International Conference on Communication Systems and Network Technologies, 2015.

[7] F. Touati, M. Al-Hitmi and H. Bouchech, "Towards understanding the effects of climatic and environmental factors on solar PV performance in arid desert regions (Qatar) for various PV technologies", First International Conference on Renewable Energies and Vehicular Technology, 2012.

[8] M. R. Maghami, H. Hizam, C. Gomes, M. A. Radzi, M. I. Rezadad, S. Hajighorbani, "Power loss due to soiling on solar panel - A review", Renewable and Sustainable Energy Reviews, 59: 1307-1316, 2016.

[9] P. A. Patil, J. S. Bagi, M. M. Wagh, "A review on cleaning mechanism of solar photovoltaic panel", International Conference on Energy, Communication, Data Analytics and Soft Computing (ICECDS), 2017.

[10] F. A. Touati , M. A. Al-Hitmi and H. J. Bouchech, "Study of the effects of dust, relative humidity, and temperature on solar PV performance in Doha, comparison between monocrystalline and amorphous PVS", International Journal of Green Energy, 10: 680689, 2013.

[11] A. Syafiq, A. K. Pandey, N. A. Rahim, "Photovoltaic glass cleaning methods - an overview", 4th IET Clean Energy and Technology Conference (CEAT), 2016.

[12] A. Al Baloushi, M. Saeed, S. Marwan, S. AlGghafri, Y. Moumouni, "Portable robot for cleaning photovoltaic system - ensuring consistent and optimal year-round photovoltaic panel performance", Advances in Science and Engineering Technology International Conferences (ASET), 2018.

[13] A. Gheitasi, A. Almaliky, N. Albaqawi, "Development of an automatic cleaning system for photovoltaic 
plants", IEEE PES Asia-Pacific Power and Energy Engineering Conference (APPEEC), 2015.

[14] M. Kegeleers, "The development of a cleaning robot for PV panels", Master Thesis, Faculty of Engineering Technology, Technology Campus De Nayer, 2015.

[15] S. T. Mobin, "Design and development of solar panel cleaning system", Master Thesis, Mechatronics and Automation, National Institute of Technology, Rourkela, 2015.

[16] H. Kawamoto and T. Shibata, "Electrostatic cleaning system for removal of sand from solar panels", IEEE 39th Photovoltaic Specialists Conference (PVSC), 2013.

[17] J. J. John, "Characterization of soiling loss on photovoltaic modules, and development of a novel cleaning system", Department of Electrical Engineering, Indian Institute of Technology, Bombay, 2015.

[18] Qi Zhang, X. Lu, J. Hu, “A solar panel cleaning system based on a linear piezoelectric actuator", Symposium on Piezoelectricity, Acoustic Waves, and Device Applications, 2013.

[19] A. Alshehri, B. Parrott, A. Outa, A. Amer, F. Abdellatif, H. Trigui, P. Carrasco, S. Patel and I. Taie, "Dust mitigation in the desert: cleaning mechanisms for solar panels in arid region", Saudi Arabia Smart Grid Conference (SASG), 2014.

[20] M. A. Jaradat, M. Tauseef, Y. Altaf, R. Saab, H. Adel, N. Yousuf and Y. H. Zurigat, "A fully portable robot system for cleaning solar panels", 10th International Symposium on Mechatronics and its Applications (ISMA), 2015.

[21] G. Du, X. Zhang, S. Wei, Q. Ji, H. Wei, "Based on the Internet of things a self-cleaning solar power system of the household micro-grid", Chinese Control and Decision Conference (CCDC), 2016.

[22] R. K. Yadav, G. Aravind, S. Agrawal,"Efficiency improvement of solar array by mitigating soil loss using Arduino", International Conference on Computer, Communications and Electronics (Comptelix), 2017.

[23] M. Z. Zulkefli, N. Rusli, N. A. Hashim, J. J. Jamian, M. N. Abdullah, "Investigation of solar photovoltaic performance via cooling-light concentrating and cleaning system using robotic arduino approach", 6th International Conference on Electrical Engineering and Informatics (ICEEI), 2017.

[24] T. G. Patil, S. Asokan, "Comparative analysis of calculation of solar panel efficiency degradation", Third International Conference on Science Technology Engineering \& Management (ICONSTEM), 2017.

[25] N. K. Memon, "Autonomous Vehicles for Cleaning Solar Panels", International Renewable and Sustainable Energy Conference (IRSEC) 2016

[26] J. Hermann, K. Slamova, R. Glaser, M. Köhl, "Modeling the Soiling of Glazing Materials in Arid Regions with Geographic Information Systems (GIS)", Energy Procedia, Vol. 48, pp. 715-720, 2014.
[27] L. Dunn, M. Gostein, "PV Module soiling measurement uncertainty analysis", 39th IEEE Photovoltaic Specialists Conference (PVSC), 2013.

[28] S. Ghazi, "Dust Effect on Flat Surfaces - A Review Paper", Renewable and Sustainable Energy Reviews 33, pp. 742-751, 2014.

[29] S. N. Sivanandam, S. Sumathi and S. N. Deepa, "Introduction to fuzzy logic using MATLAB", Springer-Verlag, Berlin, Heidelberg, 2007. 